Voix et Images

voixetimages

\title{
L'universel à l'épreuve des différences
}

\section{Stéphane Inkel}

Volume 37, numéro 1 (109), automne 2011

URI : https://id.erudit.org/iderudit/1006467ar

DOI : https://doi.org/10.7202/1006467ar

Aller au sommaire du numéro

Éditeur(s)

Université du Québec à Montréal

ISSN

0318-9201 (imprimé)

1705-933X (numérique)

Découvrir la revue

Citer ce compte rendu

Inkel, S. (2011). Compte rendu de [L'universel à l'épreuve des différences]. Voix et Images, 37(1), 131-136. https://doi.org/10.7202/1006467ar d'utilisation que vous pouvez consulter en ligne.

https://apropos.erudit.org/fr/usagers/politique-dutilisation/ 


\section{E S S A I S / ÉT U D E S}

L'universel à l'épreuve des différences

$+++$

STÉPHANE INKEL

Université Queen's

L'une des notions les plus casse-tête des sciences humaines est certainement celle d'universel. Si Gaston Miron se plaisait à dire que l'on n'atteint cet universel qu'à partir du particulier, on sait que sa consécration actuelle aura nécessité de le "dépayser ${ }^{1}$ ». On pourrait percevoir le même phénomène dans la réception du seul recueil de poèmes rédigé en portugais et publié de son vivant par Fernando Pessoa, poète par excellence du multiple et du déracinement. Car tout entier consacré au destin du Portugal, traversé par ce singulier courant messianique qu'est le sébastianisme, Message fut d'abord acclamé par le courant nationaliste portugais et primé par le secrétariat de la Propagande nationale de l'«État nouveau » de Salazar, avant que sa visée universaliste, pourtant transparente («Toutes les nations sont des mystères./À soi seule chacune est le monde entier ${ }^{2}$.»), ne s'impose et fasse aujourd'hui l'objet d'une publication sous l'égide de l'UNESCO. À ce titre, on peut considérer que cette question de l'universel concerne au premier chef les cultures mineures, au premier rang des luttes pour la diversité. C'est ce que reconnaît l'Association internationale des études québécoises (AIEQ) en publiant les actes de son premier colloque, sous la direction d'Yvan Lamonde et Jonathan Livernois ${ }^{3}$, sur cette épreuve de l'universel.

Pour donner quelques balises à cette question très large, le collectif s'ouvre sur une riche réflexion de Georges Leroux qui s'emploie, à partir d'une relecture de Problèmes de culture au Canada français de Pierre Angers, à distinguer deux manières d'envisager l'universel: comme un trésor commun en voie de totalisation dans lequel chaque nation verse ce qu'elle a en propre - suivant en cela le «principe de présomption » formulé par la pensée de la reconnaissance selon lequel nous devons «présumer une capacité de contribution universelle égale» (7) - ; ou, à l'opposé, comme un mouvement de «révélation historique du nécessaire» (3). Mais entre ces deux

1 Voir Pierre Nepveu, "Miron dépaysé», Les mots à l'écoute. Poésie et silence chez Fernand Ouellette, Gaston Miron et Paul-Marie Lapointe, Québec, Presses de l'Université Laval, coll. "Vie des lettres québécoises», 1979, 304 p. 2 Fernando Pessoa, Mensagem/Message, édition bilingue, traduit du portugais par Bernard Sesé, Paris, José Corti/Éditions UNESCO, 1988, p. 47. 3 Yvan Lamonde et Jonathan Livernois (dir.), Culture québécoise et valeurs universelles, Québec, Presses de l'Université Laval, coll. «Cultures québécoises », 2010, 451 p. 
manières, qui sont aussi deux rapports au monde qui engagent des actions - notamment d'«effacement de la différence au profit de la nécessité» (4) - , se profile une autre option autrement inquiétante : l'avènement d'une "uniformité non nécessaire » favorisée par les puissances économiques du capitalisme aujourd'hui triomphant, et dont il faut rappeler la contingence de la puissance historique. À travers une relecture de ce qui différencie l'universalité du droit de type kantien, gardant une place à la différence des cultures, de celle de la science, chez Hegel, où chaque « entité universelle concrète» serait prise « dans un devenir qui [la] fait évoluer vers une forme supérieure» (14), il s'agit pour le philosophe de circonscrire ce qui permettrait d'éviter ce qu'il appelle «l'aporie de l'universel aujourd'hui » : « ou bien une ségrégation qui mise tout sur la singularité, et promeut une particularité qui exclut et sépare, ou bien une dilution dans l'universel qui exténue en les supprimant toutes les particularités qui pourraient se trouver en excès sur l'universel » (7). Si Leroux choisit l'œuvre d'Angers pour mesurer la situation québécoise face à ces différents écueils, c'est en tant qu'elle exemplifie le moment déterminant où cette société jusqu'à tout récemment «prémoderne », contenant elle aussi une forme d'universalité, doit choisir entre le repli sur sa différence et l'accès à l'universalité de la science et de la technologie - qui est aussi un arrachement au sol de la tradition, comme Fernand Dumont l'avait bien compris. Sans nier la richesse d'une société qui, à l'égal de l'Irlande ou du Portugal, suivant les exemples choisis par Leroux ${ }^{4}$ en raison de la prégnance du catholicisme qu' on y retrouve, était fondée sur la sagesse populaire et la «tradition caritative inspirée par le catholicisme» (9), le défi de la modernité consisterait alors à " penser que l’histoire est le milieu de transformation de ces essences [que possède chaque culture] et qu'aucune ne préexiste à cette histoire» (18), manière de réconcilier la part normative de toute universalisation avec l'indétermination et la nécessaire liberté de tout devenir.

Pour faire suite à cette brillante entrée en matière, il y en a véritablement pour tous les goûts dans cet ouvrage très riche, touffu même (28 contributions et 450 pages bien comptées), selon le principe aujourd'hui érigé en vertu de l'interdisciplinarité qu'un champ aussi vaste que les études québécoises, auquel souscrit le collectif, favorise. Les enjeux balisés par Leroux pourront donc ici servir de guide. Si certaines contributions se révèlent tout à fait valables et permettent, par cet éclairage suscité par la question de l'universel, de formuler de nouvelles interprétations des œuvres de Gabrielle Roy ou de Michel Tremblay aussi bien que des essais sur la culture du sociologue Fernand Dumont, force est de constater qu'à l'exception de quelques chapitres - notamment celui de l'historienne Helga Elisabeth BoriesSawala consacré à une étude comparative de la crise des accommodements raisonnables, au Québec, avec la longue saga politique du voile islamique en France et d'un débat allemand sur l'éducation ${ }^{5}$ - , peu parviennent à se hisser à la hauteur des

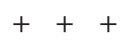

4 À la suite de Jacques Ferron et de Victor-Lévy Beaulieu. 5 Helga Elisabeth Bories-Sawala, «Interculturalité et accommodements raisonnables au Québec, laïcité républicaine à la française, mosaïque fédérale allemande», p. 399-416. Cette étude comparative permet de remarquer que les trois pays éprouvent un «certain malaise» face à l'immigration et l'établissement à demeure de cultures minoritaires, mais que celui-ci est «plus aigu en Europe qu'au Québec» (415). 
enjeux éthiques sous-jacents à cette rencontre d'une culture et des valeurs prêtées à l'universel. Ne pouvant aborder - ni même nommer - toutes les contributions qui le mériteraient, j'irai donc de simples remarques visant à donner un aperçu de l'ouvrage.

Premier sujet d'étonnement, d'ailleurs souligné par les responsables du collectif dans leur avant-propos: la faveur dont jouit l'œuvre de Fernand Dumont, qui fait l'objet de pas moins de trois chapitres. Serge Cantin, son commentateur le plus fervent, retourne au concept de dédoublement, clef de voûte de la théorie de la culture de son chef-d'œuvre, Le lieu de l'homme, à partir des mémoires du sociologue, Récit d'une émigration - où celui-ci évoque longuement la blessure de son arrachement à la culture populaire et le sentiment de trahison qui l'a accompagné - et fait la démonstration du brio avec lequel Dumont aurait relevé «le défi de penser à partir du Québec, c'est-à-dire d'atteindre l'universel à même le particulier québécois, comme l'a fait dans son domaine propre un Michel Tremblay " (192), notamment parce que cet arrachement a coïncidé avec la transformation majeure de la société. Ce serait le rôle de la culture de servir de médiation afin de réduire le fossé entre les exigences de l'universalisation et la persistance d'une mémoire, tout comme celui qui sépare l'intellectuel du «silence de ceux qui n'ont pas la parole» (200). C'est à cette même conclusion que parvient Yvan Lamonde dans sa réflexion sur «La recherche d'universel et de médiations dans la pensée québécoise (1930-1960)» (149-169), après avoir passé en revue les différents modes d'universalisation proposés face à l'effritement des deux référents traditionnels de l'identité canadienne-française, à partir de la Crise des années 1930, qu'étaient le nationalisme et le catholicisme, de «l'esprit universaliste libre» (153) du christianisme proposé par La Relève à «l'Internationalisme abstrait» (166) de Cité libre.

Du côté des études littéraires, faut-il s'en surprendre, la part du lion revient aux écrivains migrants et à la notion de transculture. Celle-ci fait ainsi l'objet d'une histoire des plus instructives, par Józef Kwaterko, de l'expérience éditoriale de la revue Dérives qui fut la première, au Québec, à mettre une telle notion de l'avant, expérience que poursuivra notamment Vice Versa dans un contexte plus favorable. Car ce qui ressort de cette expérience suffisamment longue pour avoir eu à multiplier les positionnements, c'est «le caractère anti-conjoncturel de Dérives, son indépendance des contraintes institutionnelles et discursives » (109), nommément son refus de tenir compte des débats entourant la question nationale, particulièrement vifs avant et même après le premier référendum. La notion se retrouve également au cœur d'une étude d'Ursula Mathis-Moser intitulée "La transculture, une "invention québécoise" de portée universelle? " (49-65), qui retrace les "sept piliers", ou lieux discursifs, où elle s'est construite, des revues Dérives et La parole métèque à Vice Versa.

Outre ces chapitres, nombreux et pas toujours neufs, consacrés à la migrance, au métissage et même à la notion de «littérature-monde» à laquelle les écrivains Jacques Godbout, Dany Laferrière et Wajdi Mouawad ont apporté leur caution, soulignons l'excellente étude d'Isabelle Boisclair consacrée au «Renouvellement de l'imaginaire des sexes» (357-371). Posant l'hypothèse que les textes issus de la société québécoise, «reconnue comme étant à l'avant-garde en matière d'égalité hommesfemmes ", devraient témoigner de ces avancées, elle constate que dans la littérature 
récente plusieurs textes "proposent des modèles identitaires inédits [...] où l'idée même de différence est dissoute» (370).

Ce filtre singulier qu'est la confrontation de l'idée d'universel avec la particularité du sol québécois donne donc lieu, au total, à une réflexion stimulante, même si l'on peut regretter un certain éparpillement. Mais c'est la nature même d'un collectif qui est ici en cause, et du refus manifeste de ses directeurs d'effectuer une sélection moindrement contraignante.

En Pierre Nepveu, les études québécoises disposent de longue date d'un lecteur attentif à la différence. Après le dossier publié en ces pages en 2008, c'est au tour de la collection «Paragraphes» de consacrer un ensemble de textes à son œuvre critique et poétique : Le marcheur des Amériques. Mélanges offerts à Pierre Nepveu, à l'occasion de sa retraite du Département des littératures de langue française de l'Université de Montréal ${ }^{6}$. Divisé, pour l'essentiel, entre les deux facettes qui dominent cette œuvre, qui ne se rencontrent qu'assez rarement, l'ouvrage se conclut de belle manière en donnant à lire, d'une part, le poème éponyme du recueil Les verbes majeurs traduit en quatre langues (anglaise, espagnole, portugaise et italienne), exercice qui fait écho à la traversée des cultures à laquelle Nepveu s'est toujours engagé, et, d'autre part, une série de poèmes de "compagnons de route» allant du regretté Paul-Marie Lapointe à des poètes plus jeunes comme Benoit Jutras ou Louis-Jean Thibault.

De Ginette Michaud à François Paré, ils sont nombreux à reconnaître la «tendance du critique à aborder le phénomène américain par ses marges » (70), comme le note avec justesse Jean Morency. C'est que le critique, loin de seulement substituer l'intériorité, la réclusion, voire le manque à être aux mythes des espaces neufs à conquérir, a fait de cette expérience subjective le contrepoids d'une expérience du pouvoir caractérisée par les conquêtes et par l'exploitation. On comprend ainsi qu'il ait pu, au fil du temps, s'intéresser aux déracinés du Nouveau Monde et à ce que François Paré désignait naguère la " culture de l'exiguïté ${ }^{7}$ ", puisque ces communautés, qui vivent à son paroxysme la difficulté de l'enracinement dans le Nouveau Monde, se voient confrontées à la nécessité de nommer cette expérience des limites. Prenant pour prétexte le premier compte rendu publié par Pierre Nepveu, consacré au recueil Mourir à Scoudouc d'Herménégilde Chiasson, Jean Morency cherche à montrer que les «images de bout du monde» (65) relevées par le critique préfigurent l'expérience de «l'anéantissement» (74) qu'il va chercher à décrire dans son maître livre à partir de l'expérience subjective du Nouveau Monde. De la mort qui guette à Scoudouc au "Complexe de Kalamazoo ${ }^{8}$ ", Morency cherche donc à repérer la continuité d'une interrogation, qu'il juge pourtant «non aboutie» (68), sur ces « écrivains de l'extrême

6 Marie-Andrée Beaudet et Karim Larose (dir.), Le marcheur des Amériques. Mélanges offerts à Pierre Nepveu, Montréal, Département des littératures de langue française de l’Université de Montréal, coll. «Paragraphes », 2010, 260 p. 7 François Paré, Les littératures de l'exiguité, Hearst, Le Nordir, 1992, 175 p. 8 D'après le titre d'un chapitre d'Intérieurs du Nouveau Monde (Montréal, Boréal, coll. «Papiers collés», 1998, 378 p.) 
frontière pour qui la relation au continent américain n'aurait même pas été exprimée sur le mode de la subjectivité et de l'intériorité» (68-69). Ils représenteraient donc à la fois le modèle d'une contre-expérience, et la pierre de touche de cette recherche du critique d'une transcendance dans l'appréhension du continent.

Ginette Michaud, pour sa part, déclare d'emblée qu'il est «impossible de séparer le poète du penseur » (23), s'appliquant par une lecture impressionniste à repérer les lieux où se creuse une place pour le sujet, (non-)lieux de perte ou de retrait où celui-ci se retrouve seul face à lui-même. Ce retournement de la négativité, disons son usage oxymorique, tel cet "Admirable néant» qu'il célèbre chez Marie de l'Incarnation, Michaud ne se contente pas de le repérer dans les lectures minutieuses des nombreuses voix féminines dans Intérieurs du Nouveau Monde, mais le retrouve également au sein de son œuvre poétique, notamment dans le « Journal d'une femme de ménage » de Lignes aériennes. Faisant de cette question du féminin le centre de sa relecture, Élisabeth Nardout-Lafarge signale la fonction essentielle de cette altérité dans la réflexion du critique. Si les lecteurs de Nepveu sont nombreux à reconnaître l'importance du contrepoint féminin dans son appréhension du Nouveau Monde, peu ont reconnu sa fonction dans L'écologie du réel. Soulignant la présence d'un dialogue constant entre l'essayiste et Nicole Brossard, Élisabeth Nardout-Lafarge suggère ainsi que Le centre blanc "lui fournit l'une des hypothèses les plus fécondes[,] celle d'un centre vide, lieu par excellence de cet "avènement" qui est "plongée dans la négativité" [...] » (151), sans compter que c'est la même Brossard qui lui suggère la notion d'écologie. D'un essai à l'autre, on s'aperçoit donc de l'importance considérable de ce dialogue constant avec les voix de femmes, d'autant plus que Nepveu choisit soigneusement celles «qui se font entendre au plus près du vide, du rien», empruntant ainsi «leur aptitude à porter la négativité sans s'y dérober, et [à] tirer précisément de là leur énergie créatrice» (157).

François Paré, pour sa part, lit les premiers recueils de Nepveu à partir des essais qui en ont accompagné l'écriture, des Mots à l'écoute à Intérieurs du Nouveau Monde. À rebours du paradigme du «dépaysement» qu'on a pu reconnaître comme fil conducteur d'une œuvre sensible à la pluralité, Paré montre bien que l'errance et l'écoute de l'autre - et ultimement l'écoute de l'autre en soi en provenance du passé - amènent le sujet à construire cet «ici qui serait à la fois un lieu de naissance et un principe de déracinement» (190). Ainsi le «sujet paradoxal», comme le nomme Paré, et qui désigne aussi bien les différents locuteurs de Nepveu que quiconque cherche à écrire de la poésie après la fin de l'effervescence des années 1960, se voit constamment tiraillé entre son indépendance à l'égard de la collectivité et sa responsabilité envers sa mémoire. C'est également cette question de la responsabilité qu'aborde Pierre Popovic dans sa relecture de la rétrospective Le sens du soleil en tant que «réponses dans l'ordre du langage » (134) à des problèmes historiques ou sociaux, selon la définition d'André Belleau qui sert ici de boussole à l'essayiste. Car ce dialogue avec l'histoire et le politique, nous dit Popovic, dépasse le seul recueil Lignes aériennes, composé à partir des lieux mêmes - et sur les lieux - de la désolation laissée en héritage par le mirage de Mirabel. Tout au plus, le cas de l'aéroport serait exemplaire d'une «théorie d'échecs qui sont autant de traces de la faillite plus globale des projets émancipateurs de la modernité» (136), ce qui dit assez ce qui sépare Nepveu de la 
génération de poètes qui l'a précédé. Ne faut-il voir alors que pessimisme dans cette parole attentive à l'échec, aux lendemains des emballements de toute sorte? Non, affirme pourtant Popovic, qui montre bien que ces faillites répétées sont tenues par le poète pour une «donnée anthropologique»:

les êtres humains s'emballent pour des propositions qu'ils élaborent afin de construire, changer, bouleverser, détruire le monde, puis, au bout de leurs efforts, qui tournent souvent à la catastrophe, le cours des choses reprend, une aube nouvelle arrive qui n'est jamais celle qu'ils avaient annoncée [...]. (139)

Si la responsabilité de l'écrivain réside donc dans une forme de lucidité, maître mot, pour le meilleur et (très souvent) pour le pire de toute une génération, celle-ci s'accompagne toujours, chez Nepveu, d'une foi empathique envers les recommencements, seraient-ils également condamnés à faillir, et s'enracine dans le rappel de la part d'indétermination réservée à l'entame d'une action sur le monde. 